\title{
Characterization of antimicrobial resistance in Staphylococcus aureus isolated from bovine mastitis in Central Ethiopia
}

\author{
Bezina Arega Emeru*, Yohannes Equar Messele, Desiye Tesfaye Tegegne, \\ Shimels Tikuye Yalew, Shelema Kelbessa Bora, Mossisa Dire Babura, MergieTaye Beyene \\ and Gebremeskel Mamu Werid
}

\begin{abstract}
Ethiopian Institute of Agricultural Research, National Agricultural Biotechnology Research Center, P. O. Box 249, Holeta, Ethiopia.
\end{abstract}

Received 30 March, 2019: Accepted 19 June, 2019

\begin{abstract}
Staphylococcus aureus is commonly associated with mastitis in dairy herds with potential public health implications. Overall, 303 samples were collected from September 2015 to July 2016 to characterize the phenotypic and genotypic pattern of drug resistance in $S$. aureus isolated from cases of clinical and sub-clinical bovine mastitis in Central Ethiopia. Milk samples were tested by using California Mastitis Test and positive samples were subjected for bacterial culture, disc diffusion test and polymerase chain reaction (PCR) to detect the presence of antimicrobial resistance. Based on California mastitis test (CMT) result and clinical examination, the prevalence of mastitis was $70.6 \%$. S. aureus was isolated from $36.9 \%$ of CMT positive samples. The phenotypic determination of antimicrobial resistance showed that the isolates were most resistant to ampicillin (80\%) followed by trimethoprim-sulfamethoxazole (23.3\%), tetracycline (15\%), streptomycin (10\%) and gentamycin $(3.3 \%)$ and equally to both erythromycin and chloramphenicol (1.6\%). Characterization of the antimicrobial resistance gene was done by using PCR. Most of the isolates (56\%) contained blaZ gene followed by ermB (33\%), ermC (13.3\%) and each ermA and msrA appeared only in $2 \%$ of the isolates. There was no isolate harboring the methicillin resistance mecA gene. Thirty six percent of the isolates contained more than one antibiotic resistance genes. The highest multidrug resistance (MDR) gene combination was observed by $b^{2} Z^{*}$ ermB $(31.25 \%)$ genes and the least frequently occurred were blaZ ${ }^{*} e r m A$ and $m s r A^{*} e r m B$ (3.12\%) each. This study showed that consumption of raw milk could be considered as a critical source of antibiotic resistant $S$. aureus.
\end{abstract}

Key words: Bovine mastitis, Staphylococcus aureus, antimicrobial resistance, Ethiopia.

\section{INTRODUCTION}

Mastitis is one of the most important diseases in dairy significant economic losses to the dairy industry. Staphylococcus aureus causes one of the most common types of chronic and cows throughout the world and is responsible for subclinical mastitis in dairy animals.
The inappropriate use of antibiotics for medication and growth enhancers in farm animals contributes for emergence of antibiotic resistant organisms. It is more than two decades since the emergence of antimicrobial resistant in staphylococci(Lowy, 2003). Staphylococci are 
the main etiological agents of mastitis in dairy cattle and cows are the second largest reservoir of $S$. aureus next to human nares and up to 75 million of cows can be infected by this bacterium form the world cattle population (Sakwinska et al., 2011; Somayyeh and Habib, 2014; Raney, 2009). The overall loss due to mastitis ranges from 31 to $749 \mathrm{~kg}$ in first lactation to losses between 117 and $860 \mathrm{~kg}$ in subsequent lactation (Hultgren and Svensson, 2009; Ostergaard and Grohn, 1999).

Although there is host range barrier among $S$. aureus lineage, some illustrates the potential hazard of animal origin $S$. aureus on human health which implies possible transmission of genotypes from one species to the other (Smith, 2015; Lowder et al., 2009). Despite the substantial economic impact and potential public health concern, the prevalence as well as the phenotypic and genotypic antibiotic resistance nature of $S$. aureus isolates are less studied in developing countries like Ethiopia. In these countries, scarce in veterinary services, shortage of variety of drugs and poor drug regulatory frameworks could lead to under dosage medication which may end up with development of antibiotic resistant organisms. On the other hand, low hygienic standards of housing and milking can disseminate mastitis causing pathogens including $S$. aureus among individual animals or farms (Marama et al., 2016).

In Ethiopia, prevalence rate ranging from 15.3 to $53.4 \%$ has been recorded from different parts of the country (Marama et al., 2016; Sori et al., 2011). However, there are few trends to detect antibiotic resistance genes and to correlate their association with the phenotypic resistance. Hence, this research intended to characterize phenotypic as well as genotypic antibiotic resistance of $S$. aureus isolated from bovine mastitis.

\section{MATERIALS AND METHODS}

\section{Sample collection and preparation}

A total of 303 lactating cows were screened for subclinical mastitis from September 2015 to July 2016 using California mastitis test (CMT). All the lactating cows were examined carefully and CMT screening procedures were done. Approximately, $2 \mathrm{ml}$ of milk was taken from each teat into the four CMT paddle indentations. Then, equal amount of CMT reagent (COX, USA) was added and swirled gently for $15 \mathrm{~s}$. The screening was done according to the procedure stated in Quinn et al. (1994). The CMT positive samples were kept in cold box and transported immediately to the National Agricultural Biotechnology Research Center Laboratory, Holetta, for further analysis.

\section{Bacterial isolation and identification}

Bacteria were cultured and identified from CMT positive milk samples. The collected samples from each quarter were streaked on blood agar base plates enriched with $7 \%$ ovine blood. The inoculums were then incubated aerobically at $37^{\circ} \mathrm{C}$ for $24 \mathrm{~h}$. After primary culture, identification of $S$. aureus was done by using microscopic and biochemical methods (Quinn et al., 2011; OIE, 2012).

\section{Antimicrobial sensitivity test}

Antimicrobial resistance patterns were determined by Kirby-Bauer disc diffusion method on Mueller-Hinton agar (Sigma-Aldrich, USA) (Kirby et al., 1966). The bacteria were inoculated on the plate at a rate of $5 \times 10^{5}$ Bacteria/ml after serial dilution determined by OD measurements according to CLSI recommendation. Antibiotic discs were placed and gently pressed by forceps on the bacterial culture spread on Mueller-Hinton agar (Sigma Aldrich, USA). The inhibition zone was measured after incubation of the plates at $37^{\circ} \mathrm{C}$ for $18 \mathrm{~h}$ under aerobic environment. The response of the isolates to each antimicrobial agent was evaluated by measuring the zone of inhibition categorized as sensitive, intermediate and resistant according to the standards recommended by CLSI (2007). The antimicrobials used in the experiment were ampicillin $(10 \mu \mathrm{g})$, chloramphenicol $(30 \mu \mathrm{g})$, gentamycin $(10 \mu \mathrm{g})$, erythromycin $(15 \mu \mathrm{g})$, tetracycline $(30 \mu \mathrm{g})$, streptomycin $(10 \mu \mathrm{g})$ and trimethoprimsulfamethoxazole $(1.25 / 23.75 \mu \mathrm{g})$.

\section{Isolation of plasmid DNA}

Plasmid DNA of the Staphylococcus isolates was performed by using Plasmid Midi Kit (QIAGEN). Single colony was taken from each isolate and inoculated into a separate $5 \mathrm{ml}$ LB Broth and incubated over night at $37^{\circ} \mathrm{C}$ in an orbital shaker. Cells were harvested by centrifugation at speed of $6000 \mathrm{~g}$ for $15 \mathrm{~min}$. The isolation procedures were performed according to the manufacturers' protocol. The concentration and the purity of the extract were measured by using a Nano-drop ND-1000 spectrophotometer (Thermoscientific, Wilmington, DE). The integrity of the plasmid DNA was assessed after electrophoresis in $1 \%$ agarose gel after mixing with gel loading dye (Thermoscientific, USA).

\section{PCR}

The genes involved in antimicrobial resistance (mecA, blaZ, ermA,ermB, ermC and msrA) were detected by PCR using the primers and cycle conditions described by Murakami et al. (1991) and Sawant et al. (2009) (Table 1). A single colony was picked and inoculated in to $10 \mathrm{ml}$ of nutrient broth (Sigma Aldrich, USA) and incubated overnight at $37^{\circ} \mathrm{C}$ in shaker incubator at speed of 100 $\mathrm{rpm} / \mathrm{min}$. Bacterial plasmid DNA was extracted using kit (Biobasic, USA) from well grown broth cultures. The PCR reaction was prepared by mixing, reaction buffer $\left(500 \mathrm{Mm} \mathrm{KCl}, 17.5 \mathrm{mM} \mathrm{MgCl}_{2}\right.$, $100 \mathrm{mM}$ Tris- $\mathrm{HCl}, \quad 0.1 \%$ TritonX-100) (Himedia, India), $10 \mathrm{~m}$ MdNTPs, $10 \mathrm{pmol}$ of each primer, $1 \mathrm{U}$ Taq DNA polymerase(Himedia, India) and Nuclease free water which was added up to $25 \mu \mathrm{l}$. PCR products were electrophoresed in $1.5 \%$ agarose gel after mixing with gel loading dye (Thermoscientific, USA) $(0.5 \mu \mathrm{g} / \mathrm{mL})$ and observed under UV illumination.

${ }^{*}$ Corresponding author. E-mail: bezinaemeru@gmail.com.

Author(s) agree that this article remain permanently open access under the terms of the Creative Commons Attribution License 4.0 International License 
Table 1. Genes involved and their oligonucleotide primers for the polymerase chain reactions.

\begin{tabular}{cll}
\hline Gene & Oligonucleotide sequences & Reference \\
\hline mecA & F- CTTTGGAACGATGCCTAATCTCAT & Murakami et al. (1991) \\
& R- AAGAGATTTGCCTATGCTTC & \\
FlaZ & F- GCTTGACCACTTTTATCAGC & \\
ermA & R- ATCGGATCAGGAAAAGGACA & \\
& F- AAGGGCATTTAACGACGAAA & \\
ermB & R- CTGTGGTATGGCGGGTAAGT & Sawant et al. (2009) \\
ermC & F- TGAAATCGGCTCAGGAAAAG & \\
& F- TGAAATCGGCTCAGGAAAAG & \\
msrA & R- CAAACCCGTATTCCACGATT & \\
\hline
\end{tabular}

Table 2. Antimicrobial resistance rate (\%) of $S$. aureus isolated from bovine mastitis.

\begin{tabular}{lcccc}
\hline \multirow{2}{*}{ Antimicrobial disc } & \multicolumn{3}{c}{ Sensitivity } & \multirow{2}{*}{ Total (\%) } \\
\cline { 2 - 3 } & Sensitive (\%) & Intermediate (\%) & Resistant (\%) & \\
\hline Erythromycin & $30(54.5)$ & $29(43.9)$ & $1(1.6)$ & $60(100)$ \\
Chloramphenicol & $55(91.6)$ & $4(6.6)$ & $1(1.6)$ & $60(100)$ \\
Gentamycin & $56(93.3)$ & $2(3.3)$ & $2(3.3)$ & $60(100)$ \\
Ampicillin & $10(16.6)$ & $2(3.3)$ & $48(80)$ & $60(100)$ \\
Tetracycline & $40(66.6)$ & $11(18.3)$ & $9(15)$ & $60(100)$ \\
Streptomycin & $45(75)$ & $9(15)$ & $6(10)$ & $60(100)$ \\
Trimethoprim sulfamethoxazole & $37(61.6)$ & $9(15)$ & $14(23.3)$ & $60(100)$ \\
\hline
\end{tabular}

\section{RESULTS}

\section{Prevalence of $S$. aureus and its antimicrobial resistance pattern by using disk diffusion method}

Out of the 303 lactating cows, 214 (70.6\%) of them were found positive by CMT for either of the four quarters. Among these 214 samples, $187(87.4 \%)$ were bacterial culture positive in which $79(36.9 \%)$ of the culture was identified as $S$. aureus. Antimicrobial resistance test was conducted for 60 of the 79 isolates. Antimicrobial resistance pattern of the $S$. aureus isolates is shown in Table 2. The isolates were resistant to ampicillin (80\%) followed by trimethoprim-sulfamethoxazole $(23.3 \%)$, tetracycline $(15 \%)$, streptomycin $(10 \%)$, gentamycin (3.3\%) and equally to both erythromycin and chloramphenicol with the least resistance (1.6\%).

\section{Determination of antimicrobial resistance genes}

Among all 45 isolates tested for the presence of antibiotic resistance gene, only $14(35 \%)$ were found free from any of the anti-microbial resistance gene (Table 3). Isolates containing antibiotic resistance genes were observed after electrophoresis of the PCR product (Figure 1).

Out of the 45 studied isolates, most of them (55\%) contain blaZ gene followed by ermB (33\%), ermC $(13.3 \%)$ and each ermA and msrA were detected in only $2 \%$ of the isolates. No isolate was detected harboring either ermA or msrA solely. The gene mecA was no detected at all (Table 3).

\section{Assessment of multi-drugresistance (MDR) genes}

Approximately $36 \%$ of the isolates contained more than one antibiotic resistance genes. The highest MDR gene combination was observed by blaZ*ermB $(22.2 \%)$ genes and the least frequently occurred combinations were blaZ ${ }^{*}$ ermA and $m s r{ }^{*}$ ermB $(2.2 \%)$ each. Combination of blaZ * ermC accounts for $8.8 \%$. The gene blaZ occurred in combination with all the erm genes (Table 4).

Among the 45 isolates in which the PCR test was 
Table 3. Distribution of antimicrobial resistance genes among isolates (out of 45).

\begin{tabular}{lccc}
\hline Gene & Solely appear (\%) & In combination with other (\%) & Total (\%) \\
\hline blaZ & $10(22.2)$ & $15(33.3)$ & $25(55)$ \\
ermA & $0(0.0)$ & $1(2.2)$ & $1(2.2)$ \\
ermB & $4(4.8)$ & $11(24.4)$ & $15(33.3)$ \\
ermC & $2(2.4)$ & $4(8.8)$ & $6(13.3)$ \\
msrA & $0(0.0)$ & $1(2.2)$ & $1(2.2)$ \\
mecA & $0(0.0)$ & $0(0.0)$ & $0(0.0)$ \\
\hline
\end{tabular}

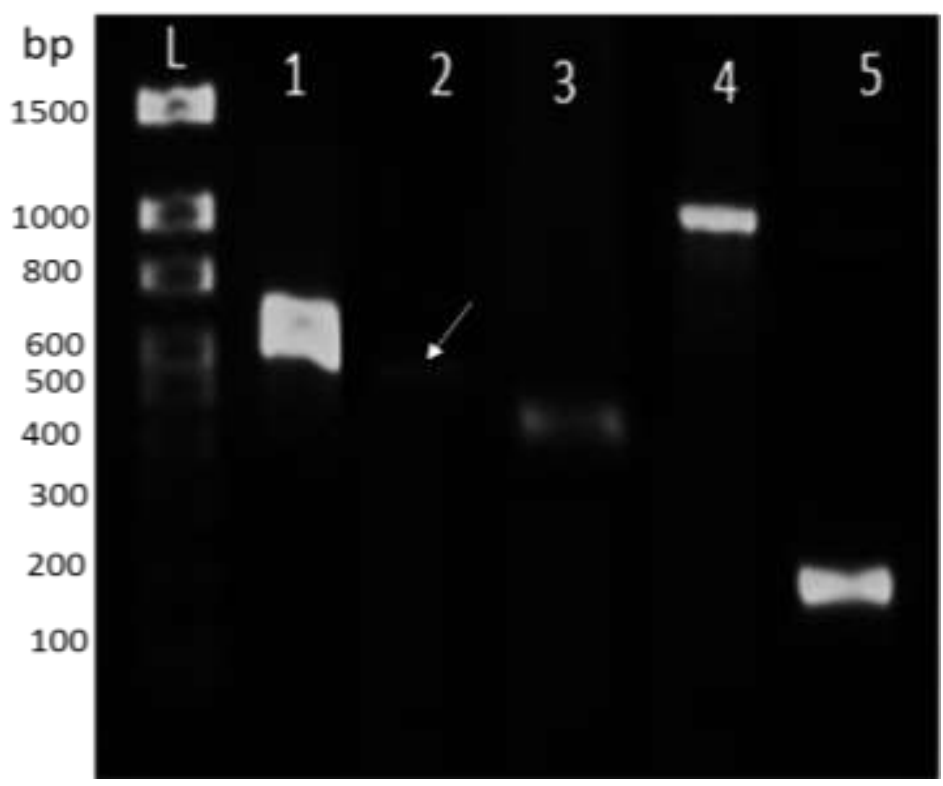

Figure 1. Agarose gel electrophoresis of representative isolates containing antibiotic resistance marker (1\%). L. Ladder (100 bp -1.5 kb DNA ladder, Bio Basic), 1.blaz (517 bp), 2.ermA (486 bp), 3.ermB (423 bp), 4.msrA (1000 bp), 5.ermC (272 bp).

Table 4. Occurrence of multiple drug resistance genes among isolates (out of 45 ).

\begin{tabular}{lc}
\hline MDR & Genes frequency (\%) \\
\hline blaZ $^{*} e r m B$ & $10(22.2)$ \\
blaZ $^{*} e r m C$ & $4(8.8)$ \\
blaZ $^{*} e r m A$ & $1(2.2)$ \\
ermB ${ }^{*} m s r A$ & $1(2.2)$ \\
subtotal & $16(35.5)$ \\
\hline
\end{tabular}

performed, 16 (35.5\%) of them showed resistance on the disc diffusion test containing the respective resistance gene. High association between ampicillin resistance and the presence of blaZ gene has been observed. Sixtyeight percent of the isolates harboring the blaZ gene were found resistant to ampicillin.

\section{DISCUSSION}

S. aureus causes one of the most common types of chronic mastitis in dairy animals worldwide. In this study, the prevalence of bovine mastitis was found in $70.6 \%$. This prevalence of mastitis is comparable with previous 
reports from Ethiopia who reported a prevalence rate of 71.0 and $75.2 \%$ in dairy farms located at Holetta and Jimma towns, respectively (Sori et al., 2011; Mekibib et al., 2009). But, higher result was found in Holetta, Bahirdar and Gondar towns of Ethiopia (Marama et al., 2016; Bitew et al., 2010; Moges et al., 2011). The difference on the prevalence of mastitis among the studies could be due to difference in management system, milking practices, productivity, breed of the animals and location (Marama et al., 2016; Sori et al., 2011).

The prevalence of $S$. aureus was found at $36.9 \%$ which is higher than the finding of Marama et al. (2016) and lower than Sori et al. (2011). In Kenya, equivalent prevalence rate $(30.6 \%)$ of $S$. aureus was reported by Shitandi and Sternesjo (2004). However, prevalence rate of $25.5,23.3$ and $10 \%$ was reported from China, Iran and Finland, respectively (Wang et al., 2008; Bahraminia et al., 2017; Pitkalla et al., 2004). The reason for the variability may be due to lactation stage of the cow, age of the cow and milking method (Kivaria et al., 2007; Ergn et al., 2009). In this study, $85 \%$ of the $S$. aureus isolates showed resistance to at least one antimicrobial drug. This is similar with the previous finding from Jimma and central Ethiopia with overall antibiotic resistance rates of 92 and 97.5\%, respectively (Sori et al., 2011; Mekibib et al., 2009). However, in Brazil relatively higher susceptibility to antimicrobials $(49.1 \%)$ was reported by Rabello et al. (2005). This variation might occur due to difference in milking practice, purpose of use of the antibiotics and inappropriate therapeutic treatment by nonprofessionals.

Considerable resistance to beta-lactam antibiotic by $S$. aureus appears with serious threat to the world (Lowy, 2003). In the current study, higher resistance to ampicillin $(80 \%)$ was observed. This is comparable with the previous reports from Gondar (81.5\%) and Italy (88\%) (Moges et al., 2011; Virdis et al, 2010), but higher than other reports from Hawassa (67.9\%) (Teshome et al., 2016). However, Daka et al. (2016) reported lower resistance rate $(7.7 \%)$ from Hawassa, Ethiopia.

Tetracycline and its derivatives are the most extensively used antibiotics in Ethiopia for treatment of animal diseases. So that, certain level of resistance to this drug was expected. The present finding on resistance against tetracycline was $15 \%$ which is nearly half of the figure observed at Gondar and Holetta with the resistance rate of 29.6 and $33.3 \%$, respectively (Moges et al., 2011;Marama et al., 2016). The most effective drugs in this experiment were gentamycin followed by erythromycin and chloramphenicol. These drugs are not first choice for treatment of mastitis in most part of the country hence the chance to develop resistance by $S$. aureus will be minimum. In contrast, there are evidences of erythromycin resistance development in some parts of the country (Moges et al., 2011; Teshome et al 2016).

Multiple drug resistance is the ability of an organism to resist and grow against two or more antimicrobials. In this study, the isolates had shown inverse relation between the multi-drug resistance nature and the number of antimicrobials applied. This observation match with the finding of Sori et al. (2011) who demonstrate MDR pattern of $25,10.45$ and $7 \%$ for two, three and four types of drugs, respectively. However, it differs from Teshome et al. (2016) who record MDR of $34.8 \%$ of the isolates for three and $8.7 \%$ for two antimicrobials. The difference observed in the pattern of MDR could be explained by group of drugs with similar chemical structure and mechanism of action may exhibit cross-resistance by the bacteria despite the number of drugs involved (Pechere, 2001).

The two main mechanisms of macrolide resistance are drug-efflux membrane pumps and modification of the drug target site in the ribosome. The third mechanism of resistance is drug inactivation (Bailey et al., 2008; Ojo et al., 2006; Jensen et al., 1999; Lina et al., 1999). It has been known that, isolates harbor erm genes (erythromycin resistance rRNA methylase) code for the protein called methyl transferase which induces N6 dimethylation of an adenine residue of $23 S$ rRNA. This process produces conformational changes in the phosphate site of the rRNA and prevents the macrolide binding at the peptidyl transferase center, hence the protein production will proceed and the bacteria will survive (Kot et al., 2012; Westh et al., 1995). Expression of the three related factors; ermA, ermB, and ermC, are responsible to make the bacteria resistance to macrolides and other related antibiotic groups (Ojo et al., 2006; Westh et al., 1995).

In the present work, among the three erythromycin resistance determinants, ermB (33.3\%) resistance gene was the most frequently identified followed by ermC (13.3\%) and ermA (2.2\%). Bahraminia et al. (2017) reported similar pattern of erm genes distribution while studying bovine mastitis caused by $S$. aureus. A work done to determine types of $S$. aureus linages affecting human showed that ermA as the most frequently found resistance gene (Bahraminia et al., 2017; Westh et al., 1995) although there are some findings supporting higher prevalence of ermC among the three determinants (Ross et al., 1990). Lina et al. (1999) correlate the distribution of erm genes with methicillin resistance and susceptibility in coagulase positive or negative staphylococci species.

The ermA gene found more common in methicillin resistant $S$. aureus stains $(57.6 \%)$ compared to the sensitive ones (5.6\%) (Westh et al., 1995).

The contribution of each of the erm determinants (ermA, ermB and erm $\mathrm{C}$ ) towards phenotypic macrolide resistance is essential. Westh et al. (1995) determined that ermA and ermC are responsible for erythromycin resistance in more than $98 \%$ of $S$. aureus strains. In another report ermC was the dominant erm gene in $S$. aureus and was responsible for erythromycin resistance in $72 \%$ of the strains in the years 1983 to 1988 (Duran et al., 2012).

In the current study, despite the high prevalence of ermB gene, we have observed only a single erythromycin 
resistance isolate $(1.6 \%)$. This finding agrees with Westh et al. (1995) which reported that ermB is less responsible for phenotypic macrolide resistance. However, we have identified a single isolate harboring this gene together with erm genes (2.2\%). The present finding showed similar results of previous works by Lina et al. (1999) and Ross et al. (1990) which identify prevalence of 3.3 and $3.6 \%$, respectively for similar combination.

Staphylococcal resistance to penicillin is attained by the gene blaZ ( $\beta$ - lactamase). It encodes for extracellular enzyme $\beta$-lactamase which hydrolyze the $\beta$-lactam ring rendering the $\beta$-lactam inactive (Lowy, 2003). In the present study, the gene was widely spread among the isolates $(80 \%)$ which are in line with the report by Duran et al. (2012). According to Lowy (2003), more than $90 \%$ of staphylococcal isolates produce penicillinase $(\beta$ lactamase enzyme). This indicates the wide distribution of the resistance gene globally through spread of resistance strains. Although blaZ is the primary key player for penicillin resistance among staphylococcus isolates, it is not the sole factor. In this study, not all isolates which show penicillin resistance by disk diffusion test harbor blaZgene. This finding agrees with previous studies by Yang et al. (2015) and Gao et al. (2012) who identified staphylococcus and streptococcus isolates that showed resistance to penicillin but not carrying blaZgene. Point mutation rather than gene acquisition could be another factor for only phenotypic resistance. Biofilm production and multi-drug efflux development are also other possible protection mechanism of the bacteria (Katayama et al., 2005; Wielders et al., 2002).

In this study, no isolate containing mecA gene was found. Similarly, another study mentioned that mecA is rarely found in many Staphylococcus isolates originated from animal infections (Ross et al., 1990). The limited distribution of Staphylococcus chromosomal cassette mec (SCCmec) which carries mecA gene by nature may be considered for its rare occurrence.

The occurrence of $S$. aureus resistance to antimicrobial agents is growing in alarming rate. So, the community should be aware by responsible bodies about the risk of consuming raw dairy products. The veterinary service delivery should be improved in order to avoid subjective treatment of animals by non-professionals. Besides, further studies should be conducted to obtain full figure of phenotypic as well as genotypic antimicrobial resistance pattern.

\section{ABBREVIATIONS}

CMT, California mastitis test; OD, optical density; PCR, polymerase chain reaction; MDR, multiple drug resistance.

\section{CONFLICT OF INTERESTS}

The authors have not declared any conflict of interests.

\section{ACKNOWLEDGEMENT}

The Ethiopian Institute of Agricultural Research covers all the financial expenses in relation to this research

\section{REFERENCES}

Bahraminia F, Emadi SR, Emaneini M, Farzaneh N, Rad M, Khoramian B (2017). A high prevalence of tylosin resistance among Staphylococcus aureus strains isolated from bovine mastitis. Veterinary Research Forum 8(2):121-125.

Bailey M, Chettiath T, Mankin AS (2008). Induction of $\operatorname{erm}(\mathrm{C})$ Expression by non-inducing antibiotics. Antimicrobial Agents and Chemotherapy 52(3):866-874.

Bitew M, Tefera A, Tolesa T (2010). Bovine mastitis in dairy farms of Bahir Dar and environs. Journal of Animal Veterinary Advances 9:2912-2917.

Clinical and Laboratory Standards Institute (CLSI) (2007). Performance Standards for Antimicrobial Susceptibility Testing; Seventeenth Informational Supplement 31:1.

Daka D, G/Silassie S, Yihdego D (2016). Antibiotic-resistance Staphylococcus aureus isolated from cow's milk in the Hawassa area, South Ethiopia. Annals of Clinical Microbiology and Antimicrobials 11:26.

Duran N, Ozer B, Duran GG, Onlen Y, Demir C (2012). Antibiotic resistance genes \& susceptibility patterns in staphylococci. The Indian Journal of Medical Research 135(3):389-396

Ergün Y, Aslantaş Ö, Doğruer G, Kireçci E, Saribay M, Ateş C, Ülkü A,Demir C (2009). Prevalence and etiology of subclinical mastitis in Awassi dairy ewes in southern Turkey. Turkish Journal of Veterinary and Animal Sciences 33(6):477-483.

França CA, Peixoto RM, Cavalcante MB, Natoniel FM, Oliveira CJB, Veschi JLA, Mota RA, Costa MM (2012). Antimicrobial resistance of Staphylococcus spp. from small ruminant mastitis in Pesquisa. Veterinária Brasileira 32(8):747-753.

Gao J, Yu F, Luo L, He JZ, Hou RG, Zhang HQ, Li SM, Su JL, Han B (2012). Antibiotic resistance of Streptococcus agalactiae from cows with mastitis. The Veterinary Journal 194:423-424.

Hultgren J, Svensson C (2009). Lifetime risk and cost of clinical mastitis in dairy cows in relation to heifer rearing conditions in southwest Sweden. Journal of Dairy Science 92(7):3274-3280.

Jensen LB, Frimodt-MÖller N, Aarestrup FM (1999). Presence of erm gene classes in Gram-positive bacteria of animal and human origin in Denmark. FEMS Microbiology Letters 170:51-158.

Katayama Y, Robinson DA, Enright MC, Chambers HF (2005). Genetic background affects stability of mecA in Staphylococcus aureus. Journal of Clinical Microbiology 43(5):2380-2383.

Kirby W, Bauer A, Sherris J, Turck M (1966). Antibiotic susceptibility testing by single disc method. American Journal of Clinical Pathology 45:4.

Kivaria FM, Noordhuizen JPTM, Nielen M (2007). Interpretation of California mastitis test scores using Staphylococcus aureus cultureresults for screening of subclinical mastitis in low yielding smallholder dairy cows in the Dar es Salaam region of Tanzania. Preventive Veterinary Medicine 78:274-285.

Kot B, Piechota M, Wolska KM, Frankowska A, Zdunek E, Binek T, Kłopotowska E, Antosiewicz M (2012). Phenotypic and genotypic antimicrobial resistance of staphylococci from bovine milk. Polish Journal of Veterinary Sciences 15(4):677-683.

Lina G, Quaglia A, Reverdy M, Leclercq R, Vandenesch F, Etienne J (1999). Distribution of genes encoding resistance to macrolides, lincosamides, and streptogramins among staphylococci. Antimicrobial Agents and Chemotherapy 43(5):1062-1066.

Lowder BV,Guinane CM,Ben Zakour NL, Weinert LA, Conway-Morris A, Cartwright RA, Simpson AJ, Rambaut A, Nübel U, Fitzgerald JR (2009). Recent human-to-poultry host jump, adaptation, and pandemic spread of Staphylococcus aureus. Proceedings of the National Academy of Sciences of the United States of America 106:19545-19550.

Lowy FD (2003). Antimicrobial resistance: the example of 
Staphylococcus aureus. Journal of Clinical Investigation 111(9):12651273.

Marama A, Mamu G, Birhanu T (2016). Prevalence and antibiotic resistance of Staphylococcus aureus Mastitis in Holetta Area, Western Ethiopia. Global Veterinaria 16(4):365-370.

Mekibib B, Furgasa M, Abunna F, Megersa B, Regassa A (2009). Bovine mastitis: prevalence, risk factors and major pathogens in dairy farms of Holetta Town, Central Ethiopia. Veterinary World 13(9):397403.

Moges N, Asfaw Y, Belihu K, Tadesse A (2011). Antimicrobial susceptibility of mastitis pathogens from smallholder dairy herds in and around Gondar, Ethiopia. Journal of Animal Veterinary advances 10(12):1616-1622.

Murakami KW, Minamide W, Wada K, Nakamura E, Teraoka H, Watanabe S (1991). Identification of methicillin resistant strains of Staphylococci by polymerase chain reaction. Journal of Clinical Microbiology 29:2240-2244.

OIE (World Organization for Animal Health) (2012). Manual of diagnostic tests and vaccines for terrestrial animals (mammals, birds and bees). $7^{\text {th }}$ ed., Vol. 2.

Ojo KK, Striplin MJ, Ulep CC, Close NS, Zittle J, Luis H, Bernardo M,Leitao J, Roberts MC (2006). Staphylococcus Efflux msr(A) Gene Characterized in Streptococcus, Enterococcus, Corynebacterium, and Pseudomonas Isolates. Antimicrobial Agents and Chemotherapy, pp. 1089-1091.

Ostergaard S, Grohn Y (1999). Effects of diseases on test day milk yield and body weight of dairy cows from Danish Research Herds. Journal of Dairy Science 82(6):1188-1201.

Pechere JC (2001). Macrolide resistance mechanisms in Gram-positive cocci. International Journal of Antimicrobial Agents 18:25-28.

Pitkalla A, Haveri M, Pyörälä S, Myllys V, Honkanen-Buzalski T (2004). Bovine mastitis in Finland 2001- Prevalence, distribution of bacteria, and antimicrobial resistance. Journal of Dairy Science (8):2433-41.

Quinn P, Markey B, Leonard F, Fitz Patrick S, Fanning S, Fitz Patrick E (2011). Veterinary microbiology and microbial disease. $2^{\text {nd }}$ ed, WileyBlackwell.

Quinn PJ, Carter ME, Markey B, Carter GR (1994). Clinical Veterinary Microbiology. Wolfe, London. p. 648.

Rabello R, Souza C, Duarte R, Lopes R, Teixeira L, Castro A (2005). Characterization of Staphylococcus aureus isolates recovered from bovine mastitis in Rio de Janeiro, Brazil. Journal of Dairy Science 88:3211-3219.

Raney T (2009). The state of food and agriculture: livestock in the balance. Food and Agriculture Organization of the United Nations, Rome, Italy.

Ross JI, Eady EA, Cove JH, Cunliffe WJ, Baumberg S, Wootton JC (1990). Inducible erythromycin resistance in Staphlyococci is encoded by a member of the ATP-binding transport super-gene family. Molecular Microbiology 4(7):1207-1214.

Sakwinska O, Giddey M, Moreillon M, Morisset D, Waldvoge A, Moreillon $P$ (2011). Staphylococcus aureus host range and humanbovine host shift. Applied and Environmental Microbiology 77(17):5908-15.
Sawant A, Gillespie B, Oliver S (2009). Antimicrobial susceptibility of coagulase negative Staphylococcus species isolated from bovine milk. Veterinary Microbiology 134:73-81.

Shitandi A, Sternesjo A (2004). Factors contributing to the occurrence of antimicrobial drug residues in Kenyan milk. Journal of Food Protection 67(2):399-402.

Smith TC (2015). Livestock-Associated Staphylococcus aureus: The United States Experience. PLOS Pathogens 11(2):e1004564. https://doi.org/10.1371/journal.ppat.1004564.

Somayyeh H, Habib D (2014). Staphylococcal species associated with bovine mastitis in the North West of Iran: Emerging of coagulasenegative staphylococci. International Journal of Veterinary Science and Medicine 2:27-34.

Sori T, Hussien J, Bitew M (2011). Prevalence and susceptibility assay of staphylococcus aureus isolated from bovine mastitis in dairy farms of Jimma Town, South west Ethiopia. Journal of Animal Veterinary advances 10(6):745-749.

Teshome B, Tefera G, Belete B, Mekuria A (2016). Prevalence and antimicrobial susceptibility pattern of Staphylococcus aureus from raw camel and goat milk from Somali region of Ethiopia. African Journal of Microbiology Research 10(28):1066-1071.

Virdis S, Scarano C, Cossu F,Spanu V, Spanu C, De Santis E (2010). Antibiotic resistance in Staphylococcus aureus and coagulase negative staphylococci isolated from goats with subclinical mastitis. Veterinary Medicine International 2010: 517060.doi: 10.4061/2010/517060.

Wang Y, Wu C, Lu L, Ren GN, Cao X, Shen J (2008). Macrolidelincosamide-resistant phenotypes and genotypes of Staphylococcus aureus isolated from bovine clinical mastitis. Veterinary Microbiology 130(1-2):118-25.

Westh H, Hougaard DM, Vuust J, Rosdahl VT (1995). Prevalence of erm gene classes in erythromycin-resistant Staphylococcus aureus strains isolated between 1959 and 1988. Antimicrobial Agents and chemotherapy 39(2):369-373.

Wielders CL, Fluit AC, Brisse S, Verhoef J, Schmitz JF (2002). mecA gene is widely disseminated in Staphylococcus aureus population. Journal of Clinical Microbiology 40(11):3970-3975.

Yang F, Wang Q, Wang X, Wang L, Xiao M, Li X, Luo J, Zhang S, Li H (2015). Prevalence of blaZ gene and other virulence genes in penicillin-resistant Staphylococcus aureus isolated from bovine mastitis cases in Gansu, China. Turkish Journal of Veterinary and Animal Sciences 39:634-636. 